\title{
Selective Determination of Epinephrine in the Presence of Ascorbic Acid Using a Glassy Carbon Electrode Modified with Graphene
}

\author{
Xia LI, Meifeng Chen, and Xinying $\mathrm{MA}^{\dagger}$ \\ Department of Chemistry and Chemical Engineering, Heze University, Daxue Road, Heze, Shandong 274015, \\ P. R. China
}

\begin{abstract}
A graphene-modified glassy carbon electrode was fabricated via a drop-casting method, and applied to the electrochemical detection of epinephrine. The capacity of the graphene-modified glassy carbon electrode for the selective detection of epinephrine was confirmed in a sufficient amount of ascorbic acid $\left(2 \mathrm{mmol} \mathrm{L}^{-1}\right)$ by cyclic voltammetry. The modified electrode showed an excellent electrocatalytical effect on the oxidation of epinephrine. A pair of well-defined redox waves were observed in voltammograms of epinephrine in a phosphate buffered solution $(\mathrm{pH} 4.0)$. The peak potentials of epinephrine remained unchanged, and the oxidation peak currents showed a linear relation versus the epinephrine concentration in the range of $3.85 \times 10^{-7}-1.31 \times 10^{-5} \mathrm{~mol} \mathrm{~L}^{-1}$ and $1.31 \times 10^{-5}-1.09 \times 10^{-4} \mathrm{~mol} \mathrm{~L}^{-1}$ with a correlation coefficient as follows: $i_{\mathrm{pa} 1}=-4.25 \times 10^{-6}-1.99 c\left(\mathrm{~mol} \mathrm{~L}^{-1}\right), R_{1}=0.9953 ; i_{\mathrm{pa} 2}=-4.31 \times 10^{-5}-0.315 c\left(\mathrm{~mol} \mathrm{~L}^{-1}\right), R_{2}=$ 0.9988. Detection limit is estimated to be $8.9 \times 10^{-8} \mathrm{~mol} \mathrm{~L}^{-1}$. Graphene-modified glassy carbon electrode was applied to epinephrine sample analysis, and the results were in good agreement with the standard values.
\end{abstract}

(Received August 18, 2011; Accepted October 31, 2011; Published February 10, 2012)

\section{Introduction}

Epinephrine (EP) is one of the most important neurotransmitters in mammalian central nervous systems, and exists in nervous tissue and body fluids. EP controls the nervous system in its performance for a series of biological reactions and nervous chemical processes. ${ }^{1}$ Many diseases are related to changes of the EP concentration in mammals. It also serves as a chemical mediator, transmitting the nerve impulses to different organs. Medically, EP has been used as a common emergency health care medicine. $^{2}$ Also, low levels of EP have been found in patients with Parkinson's disease. ${ }^{3}$ The quantitative determination of EP is significant in developing nerve physiology, diagnosis and controlling medicine. ${ }^{4}$ To date, the ability to detect EP with high selectivity and sensitivity is still a major target of electroanalytical research. ${ }^{5,6}$ The main problem of measuring this monoamine in vivo is the very low EP concentration and the large excesses of interfering substances, such as ascorbic acid (AA). Unfortunately, at most solid electrodes, AA is oxidized at a potential close to that of EP, resulting in an overlapping voltammetric response. In order to resolve this problem, one of the most common routes is to use a modified electrode, which can eliminate the interference of AA to EP determination. ${ }^{7,8}$

Nanomaterial-modified electrodes have been successfully used for electrochemical studies of EP due to their unusual characteristics. ${ }^{9,10}$ These methods showed good sensitivity, selectivity, stability and a low detection limit because of the

$\dagger$ To whom correspondence should be addressed.

E-mail: cmf369@ sohu.com unique electronic and catalytic properties of nanomaterials. Graphene, the 2D honeycomb lattice of $\mathrm{sp}^{2}$-bonded carbon atoms, has attracted tremendous attention from both theoretical and experimental scientific communities in recent years. Graphene has a large surface area, excellent conductivity, and strong mechanical strength. ${ }^{9-14}$ To the best of our knowledge, there is no report based on using graphene-modified electrodes for the determination of EP in the presence of AA.

In this study, a novel electrochemical sensor was fabricated with graphene-modified glassy carbon electrodes (GME), and the electrochemical properties were investigated. The results show that the graphene-modified electrode exhibits excellent performance for selectively detecting EP in the presence of AA.

\section{Experimental}

\section{Reagents and chemicals}

Graphite powder $(<20 \mu \mathrm{m})$ was purchased form Qingdao Graphite Co., Ltd. (China), sodium borohydride from Tianjin Daofu Chemical New Technique Development Co., Ltd. (China), and EP and AA from National Institute for the Control of Pharmaceutical and Biological Products (China). Phosphate buffer solutions (PBS) were prepared by mixing dipotassium hydrogen phosphate $\left(\mathrm{K}_{2} \mathrm{HPO}_{4}\right)$ and citric acid $\left(\mathrm{C}_{6} \mathrm{H}_{8} \mathrm{O}_{7}\right)$, both of which were purchased from Beijing Chemical Reagent Co. (China). All other chemicals not mentioned here were of analytical reagent grade, and were used as received. Double-distilled water was used throughout. Graphene was made as described below. 


\section{Apparatus}

Electrochemical experiments were performed with an Electrochemical Work Station-CHI660C (CH Instruments, Shanghai Chenhua Instrument Corp., China). An infrared spectroscopy (IR) study of the chemical functional groups on the exfoliated graphite and graphene was conducted on a Varian660-IR (Agilent Technologies, America). A conventional three-electrode system was used throughout. The working electrode was a bare glassy carbon electrode (GCE) or GME ( $3 \mathrm{~mm}$ in diameter $(\phi)$ ), the auxiliary electrode was a Pt electrode, and an $\mathrm{Ag} / \mathrm{AgCl}$ electrode was employed as a reference electrode. PHS-3B was purchased from Shanghai Precision Scientific Instrument Co., Ltd. (China), and KQ-100 ultrasonic cleaner was provided by Kunshan Ultrasonic Instrument Factory (China).

\section{Preparation of the nano-graphene}

Graphene oxide (GO) was made by a modified Hummers method $^{15}$ using expandable graphite flake as the starting material; graphite flake $(4 \mathrm{~g})$ was stirred in $98 \% \mathrm{H}_{2} \mathrm{SO}_{4}(92 \mathrm{~mL})$ for $8 \mathrm{~h}$. $\mathrm{KMnO}_{4}(12 \mathrm{~g})$ was gradually added while keeping the temperature at $<36^{\circ} \mathrm{C}$ for $0.5 \mathrm{~h}$. The mixture was then stirred at $80^{\circ} \mathrm{C}$ for $45 \mathrm{~min}$, and then water $(184 \mathrm{~mL})$ was added and the mixture heated at $95-105^{\circ} \mathrm{C}$ for $30 \mathrm{~min}$. The reaction was terminated by the addition of distilled water $(184 \mathrm{~mL})$ and a $30 \% \mathrm{H}_{2} \mathrm{O}_{2}$ solution $(40 \mathrm{~mL})$. The mixture was washed by repeated centrifugation and filtration, first with a $5 \% \mathrm{HCl}$ aqueous solution, and then with distilled water, until no $\mathrm{SO}_{4}{ }^{2-}$ was detected by $\mathrm{BaCl}_{2}$. The final product was dried at $50^{\circ} \mathrm{C}$ for $24 \mathrm{~h}$ and stored for further use.

Graphene ${ }^{16,17}$ was obtained in a jacketed vessel by dispersing purified GO $(0.5 \mathrm{~g})$ in distilled water $(500 \mathrm{~mL})\left(1 \mathrm{~mol} \mathrm{~L}^{-1}\right)$ with the aid of intensive sonication $(100 \mathrm{~W}, 40 \mathrm{kHz}, 1 \mathrm{~h})$. To prepare an aqueous GO suspension ( $\mathrm{pH} 10.0$ ), sodium carbonate was added into the jacketed vessel. The temperature was strictly controlled at $80^{\circ} \mathrm{C}$ by a constant-temperature circulator, while sodium borohydride $(5 \mathrm{~g})$ was added. The mixture was then stirred at $80^{\circ} \mathrm{C}$ for $1.5 \mathrm{~h}$. The powder of graphene was obtained by filtration and drying in a vacuum.

\section{Preparation of graphene-modified electrode (GME)}

A graphene suspension (GS) was made by graphene dispersing in doubly distilled water at a concentration of $0.7 \mathrm{mg} \mathrm{mL}^{-1}$. GCE $(\phi=3 \mathrm{~mm})$ was polished before each experiment with gold sand paper and $0.05 \mu \mathrm{m}$ alumina powder, respectively, rinsed thoroughly with doubly distilled water between each polishing step, then washed successively with 1:1 nitric acid, ethanol and doubly distilled water in ultrasonic bath, and dried in air. GME was prepared by casting $4 \mu \mathrm{L}$ of GS suspension on the GCE and dried under an infrared lamp.

\section{Determination of EP}

Under optimal conditions, a series of different concentrations of EP were investigated by cyclic voltammetry in a PBS solution ( $\mathrm{pH}$ 4.0). A three-electrode system was used, including a GME as the working electrode, a platinum electrode as a counter electrode, and $\mathrm{Ag} / \mathrm{AgCl}\left(1 \mathrm{~mol} \mathrm{~L}^{-1} \mathrm{KCl}\right)$ as a reference electrode. Cyclic voltammograms (CVs) of EP were recorded. The GCE carbon electrode was restored by repetitive scanning under optimal conditions until no record. The GME was dried with filter paper and used again.

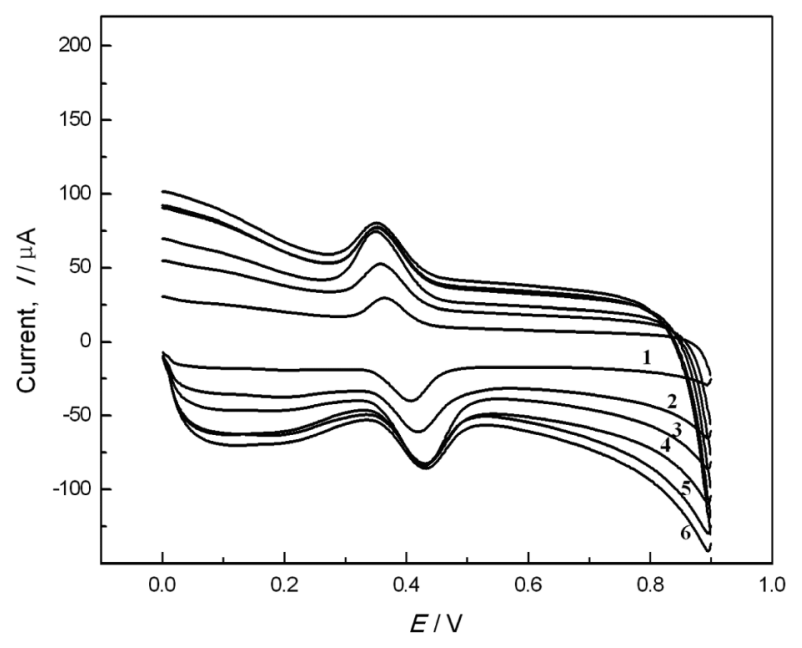

Fig. $1 \mathrm{CVs}$ of $5.0 \times 10^{-5} \mathrm{~mol} \mathrm{~L}^{-1} \mathrm{EP}$ in PBS $(\mathrm{pH} 4.0)$ were obtained using GCE modified with different concentrations of GS from 0.3 to $1.4 \mathrm{mg} \mathrm{mL}^{-1}$. Concentration of GS: $1,0.3 ; 2,0.5 ; 3,0.7 ; 4,1.0 ; 5,1.2$; 6, $1.4 \mathrm{mg} \mathrm{mL}^{-1}$.

\section{Results and Discussion}

\section{Optimization of GME}

GME was prepared at different concentrations of GS from 0.3 to $1.0 \mathrm{mg} \mathrm{mL}^{-1}$, as described under "Experimental". The measurements were made in the potential range between 0.0 and $0.9 \mathrm{~V}$ at a scan rate of $140 \mathrm{mV} \mathrm{s}^{-1}$ and $5.0 \times 10^{-5} \mathrm{~mol} \mathrm{~L}^{-1}$ of EP in PBS ( $\mathrm{pH} 4.0$ ) after the solution was stirred for $1 \mathrm{~min}$.

As shown in Fig. 1, the peak current $\left(I_{\mathrm{p}}\right)$ significantly increased with increasing concentration of GS from 0.3 to $0.5 \mathrm{mg} \mathrm{mL}^{-1}$, and then slightly increased from 0.5 to $0.7 \mathrm{mg} \mathrm{mL}^{-1}$. However, the $I_{\mathrm{p}}$ decreased while the concentration of GS exceeded $1.0 \mathrm{mg} \mathrm{mL}^{-1}$, which may be ascribed to the thicker graphene film hampering the electrical conductivity and the availability an electrical catalyst on the electrode surface. Meanwhile, catalytic substrates have been hampered to spread to the electrode surface. Thus, we used $4 \mu \mathrm{L}$ of a $0.7 \mathrm{mg} \mathrm{mL}^{-1}$ suspension to prepare the GME as the working electrode in our experiments.

The amount of deposited graphene on GCE was affected by not only the concentration but also the volume of GS. Therefore, we investigated the effect of the volume of GS casted on GCE on the current peak of EP by cyclic voltammetry. At the optimal concentration $\left(0.7 \mathrm{mg} \mathrm{mL}^{-1}\right)$ of GS used for GME preparation, $I_{\mathrm{p}}$ of EP clearly increased with increasing the volume of GS casted on GCE from 1 to $5 \mu \mathrm{L}$, and then decreased while the amount of graphene suspension exceeded $5 \mu \mathrm{L}$. High loading of graphene increased both the peak current and the capacitive background current, but excessive loading induced a large increase of capacitive background current, which may lead to the reduction of the cyclic voltammetry peak current. In our experiments, the volume of GS used to prepare GME was kept at $5 \mu \mathrm{L}$.

\section{Characterization of graphene by $I R$}

Figure 2 shows an image of IR of graphite and graphene. The functional groups and wave numbers of graphene are listed in Table 1. These results show that graphene was synthesized successfully. ${ }^{17}$ Graphene sheets contain abundant C-O-C (epoxide) and $\mathrm{C}-\mathrm{OH}$ groups, while the sheets are terminated with $\mathrm{C}-\mathrm{OH}$ groups. ${ }^{18}$ The functionalized and defective graphene 


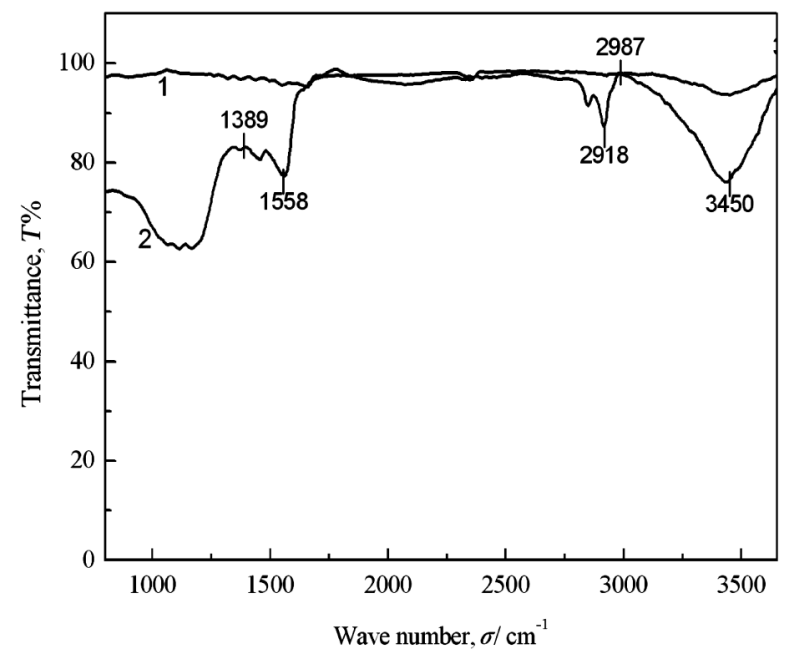

Fig. 2 IR of graphite and graphene. 1, Graphite; 2, graphene.

Table 1 Functional groups and wave numbers of graphene

\begin{tabular}{cc}
\hline Functional group & Wave number, $\sigma / \mathrm{cm}^{-1}$ \\
\hline$-\mathrm{OH}$ & 3450 \\
$\mathrm{C}=\mathrm{C}$, phenyl & $1300-1600$ \\
C-O-C & $1110-1200$ \\
\hline
\end{tabular}

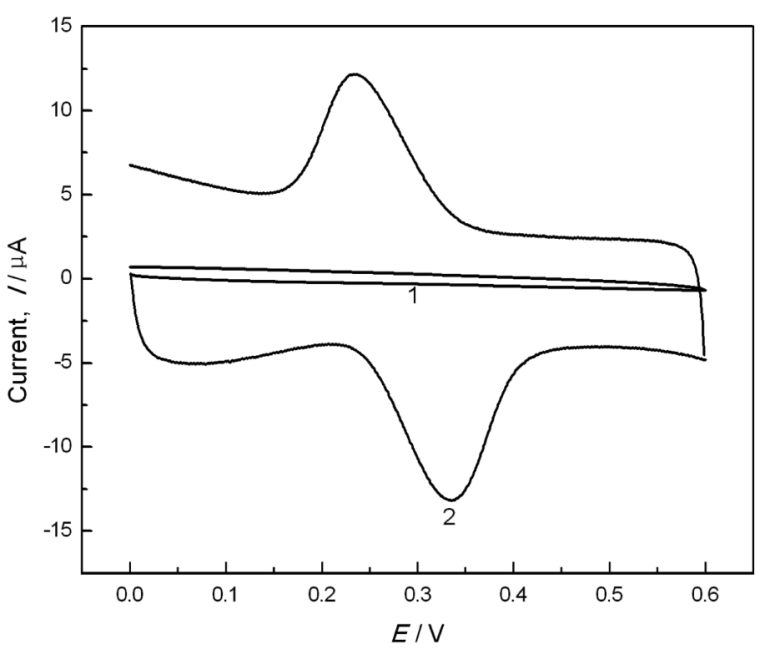

Fig. $3 \mathrm{CVs}$ of $5.0 \times 10^{-5} \mathrm{~mol} \mathrm{~L}^{-1} \mathrm{EP}$ in PBS (pH 4.0) obtained at the bare GCE and the GME at a scan rate $140 \mathrm{mV} \mathrm{s}^{-1}$. 1, Bare GCE; 2, GME.

sheets are more hydrophilic, and can be easily dispersed in solvents with long-term stability.

\section{Electrochemical behaviors of EP on GME}

Figure 3 shows the CVs of $5.0 \times 10^{-5} \mathrm{~mol} \mathrm{~L}^{-1}$ EP in PBS $\left(0.1 \mathrm{~mol} \mathrm{~L}^{-1}, \mathrm{pH} 4.0\right)$ at GCE and GME. The peak-current intensity at GME was sharply increased, and in contrast the peak-current is near zero at GCE, which confirms that graphene has excellent electrocatalytic activity to EP. Such electrocatalytic behavior of graphene is attributed to its unique physical and chemical properties. In general, graphene has a large surface

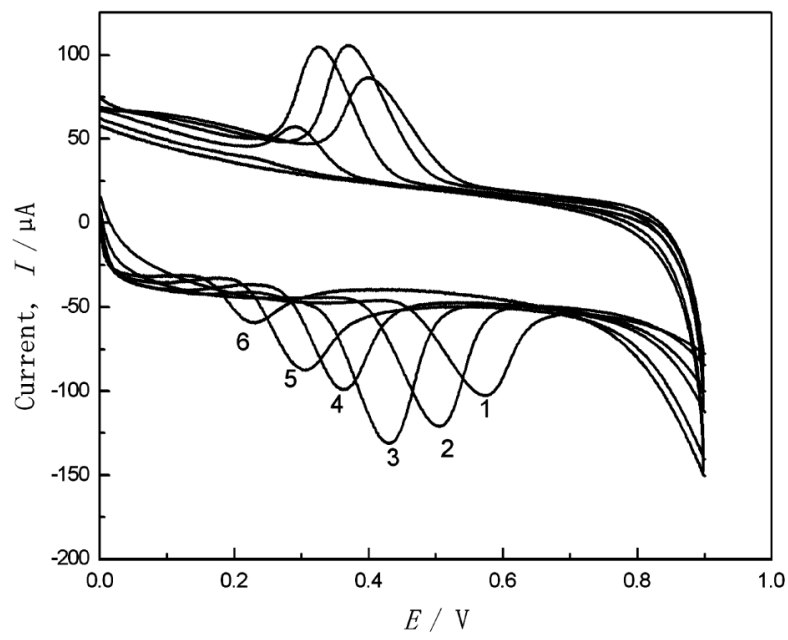

Fig. $4 \mathrm{CVs}$ of $5.0 \times 10^{-5} \mathrm{~mol} \mathrm{~L}^{-1} \mathrm{EP}$ on $\mathrm{GME}$ at scan rate $140 \mathrm{mV} \mathrm{s}^{-1}$ in PBS with different $\mathrm{pH}$ values from 2.2 to 7.0. The $\mathrm{pH}$ value of PBS: $1,2.2 ; 2,3.0 ; 3,4.0 ; 4,5.0 ; 5,6.0 ; 6,7.0$.

area, excellent conductivity, and strong mechanical strength. These unique features may endue the functionalized graphene with unique electronic and chemical properties. As a novel electrochemical sensor, GME shows excellent performance for detecting EP. The peak currents at the GME was $i_{\mathrm{pa}}=-56.59 \mu \mathrm{A}$, $i_{\mathrm{pc}}=55.36 \mu \mathrm{A}$ and $i_{\mathrm{pa}} / i_{\mathrm{pc}} \sim 1$, suggesting that the redox performs a reversible process. The sensor shows great promise for the simple, sensitive, and quantitative detection of EP.

\section{Optimization of the experimental conditions}

The effect of the medium's $\mathrm{pH}$ on the electrochemical signal was analyzed. Figure 4 shows the important influence of the $\mathrm{pH}$ on the redox reaction of EP at the GME. As we can see, with increasing $\mathrm{pH}$ value of the solution, the redox peak negatively shifted; based on $E_{\mathrm{p}}=\left(E_{\mathrm{pa}}+E_{\mathrm{pc}}\right) / 2$, the equation was $E_{\mathrm{p}}=0.66-0.059 \mathrm{pH}, R=0.9977$. According to the Nernst equation, the slope of $-59 \mathrm{mV} \mathrm{pH}^{-1}$ reveals that the proportion of electrons and protons involved in the reactions was 1:1. Since EP oxidation is a two-electron process, the number of protons involved is also predicted to be two. Therefore, a mechanism for EP oxidation can be proposed in Eq. (1). This is in agreement with a previous report. ${ }^{19-21}$

The $\mathrm{pH}$ of EP solutions changed from $\mathrm{pH} 2.2$ to 7.0, and the potential was scanned in the range of $0.0-0.9 \mathrm{~V}$. The redox peak currents increased as the $\mathrm{pH}$ changed from 2.2 to 4.0 , and then decreased after $\mathrm{pH}>4.0$, indicating that the redox reactions involve protons. Thus, a buffer solution of $\mathrm{pH} 4.0$ was chosen as the supporting electrolyte in this work.

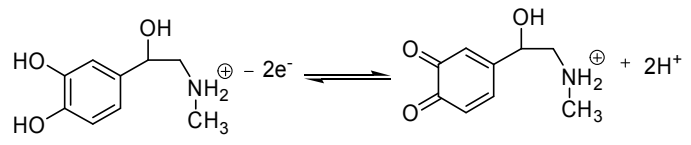

The oxidation potentials of EP moved to the positive direction and the redox peak currents increased, with the scan rates ranging from 20 to $380 \mathrm{mV} \mathrm{s}^{-1}$ (Fig. 5). The linear-regression equations of $i_{\mathrm{pa}}$ and $i_{\mathrm{pc}}$ of the scan rates are expressed as $i_{\mathrm{pa}}(\mathrm{A})=-3.13 \times 10^{-5}-3.75 \times 10^{-7} v \quad(\mathrm{mV}), \quad R=0.9963 ;$ $i_{\mathrm{pc}}(\mathrm{A})=5.58 \times 10^{-6}+5.45 \times 10^{-7} v \quad(\mathrm{mV}), \quad R=0.9952$, respectively, indicating that the electrochemical behaviors of EP on GME is an adsorption process. If the GME was taken out from the solution of EP, we can know that the redox peak 


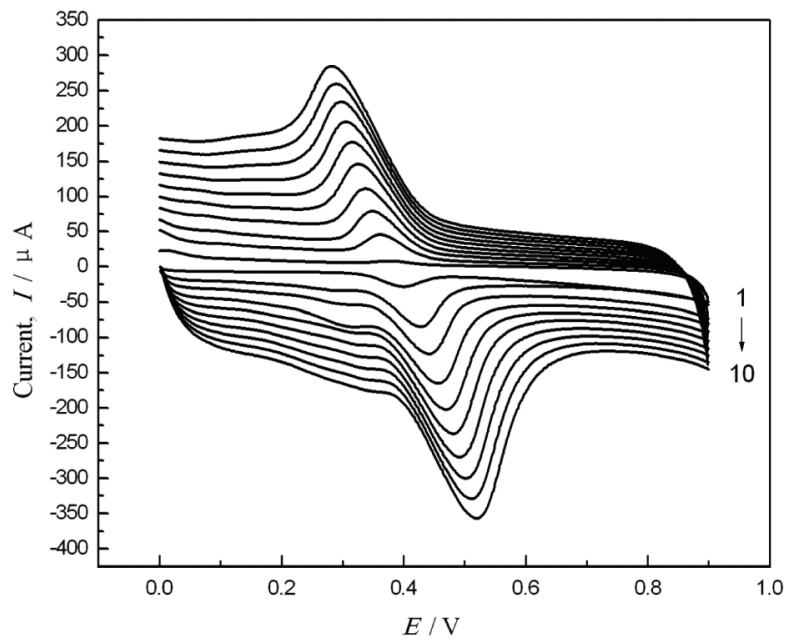

Fig. $5 \mathrm{CVs}$ of EP on GME in the buffer of PBS $\left(0.1 \mathrm{~mol} \mathrm{~L}^{-1} \mathrm{pH} 4.0\right)$ at different scan rates from 20 to $380 \mathrm{mV} \mathrm{s}^{-1}$. Scanning rate: 1,$20 ; 2$, $60 ; 3,100 ; 4,140 ; 5,180 ; 6,220 ; 7,260 ; 8,300 ; 9,340 ; 10,380 \mathrm{mV} \mathrm{s}^{-1}$.

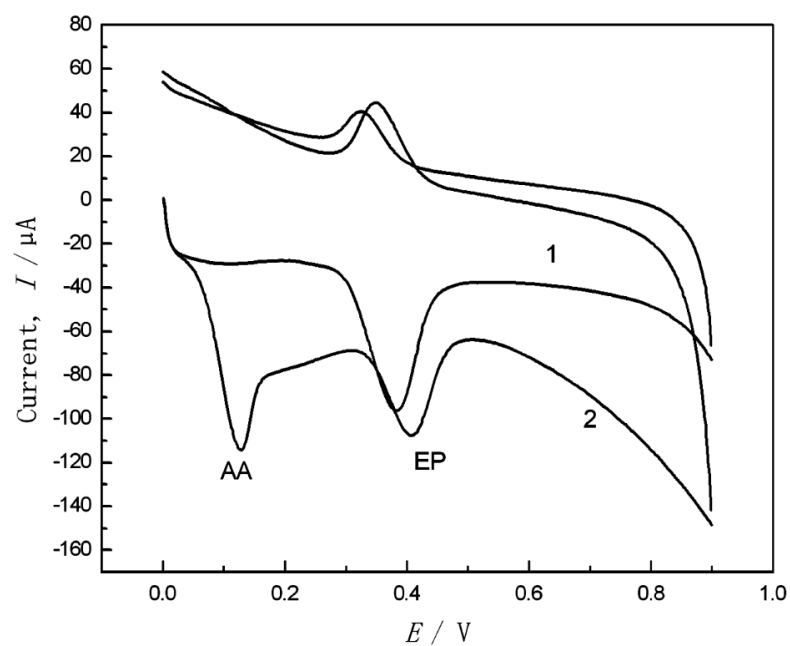

Fig. $6 \mathrm{CVs}$ of EP and a mixture of EP and AA in PBS on GME. Content: $1,5.0 \times 10^{-5} \mathrm{~mol} \mathrm{~L}^{-1} \mathrm{EP} ; 2,2.5 \times 10^{-5} \mathrm{~mol} \mathrm{~L}^{-1} \mathrm{EP}$ and $2.0 \times$ $10^{-3} \mathrm{~mol} \mathrm{~L}^{-1} \mathrm{AA}$. currents still existed after scanning in a blank PBS solution; but with the scanning time after the time that it decreased sharply until it disappeared completely. It may also be ascribed to an adsorption process of the electrochemical behaviors of EP on GME. However, the symmetry of the potential becomes worse with the scan rates, ranging after $140 \mathrm{mV} \mathrm{s}^{-1}$. Therefore, $140 \mathrm{mV} \mathrm{s}^{-1}$ was used as the scan rate.

Our study of the variation of the accumulation time enabled us to ascertain the level of EP adsorption on the electrode surface. To accomplish this, we recorded the CVs of $20,40,60,80,100$, 120 , and $140 \mathrm{~s}$ of the accumulation time for $5.0 \times 10^{-5} \mathrm{~mol} \mathrm{~L}^{-1}$ $\mathrm{EP}$, and an equilibration between the substance concentration on the surface of the electrode and EP was reached with shaking. The $I_{\mathrm{p}}$ of EP increased significantly with the increase of the accumulation time, and reached a maximum at $120 \mathrm{~s}$, suggesting that graphene can effectively accumulate EP. Therefore, $120 \mathrm{~s}$ was used as the accumulation time.

\section{Effect of the EP concentration and the detection limit}

To quantitively detect $\mathrm{EP}$, the concentrations of EP were varied from $3.85 \times 10^{-7}$ to $1.09 \times 10^{-4} \mathrm{~mol} \mathrm{~L}^{-1}$. The peak potentials of EP remained unchanged, and the oxidation peak currents of EP showed a linear relation versus $\mathrm{EP}$ concentration in the range of $3.85 \times 10^{-7}-1.31 \times 10^{-5} \mathrm{~mol} \mathrm{~L}^{-1}$ and $1.31 \times$ $10^{-5}-1.09 \times 10^{-4} \mathrm{~mol} \mathrm{~L}^{-1}$ with a correlation coefficient as follows: $i_{\mathrm{pa} 1}=-4.25 \times 10^{-6}-1.99 c\left(\mathrm{~mol} \mathrm{~L}^{-1}\right), R_{1}=0.9953$; and $i_{\mathrm{pa} 2}=-4.31 \times 10^{-5}-0.315 c\left(\mathrm{~mol} \mathrm{~L}^{-1}\right), R_{2}=0.9988$. The detection limit is estimated to be $8.9 \times 10^{-8} \mathrm{~mol} \mathrm{~L}^{-1}$.

\section{Interference studies}

AA often coexists with EP in physiological fluids and possesses close oxidation potentials to $\mathrm{EP}$ at a bare electrode. In this study, it was found that the above problem could be resolved by using the GME. Thus, it provides a possible method for the selective determination of $\mathrm{EP}$ in a mixture solution containing EP and AA. In order to confirm the availability of GME to the selective determination of EP in the presence of AA, as shown in Fig. 6, we scanned a solution of $5.0 \times$ $10^{-5} \mathrm{~mol} \mathrm{~L}^{-1} \mathrm{EP}(1)$ and a mixture containing $2.5 \times 10^{-5} \mathrm{~mol} \mathrm{~L}^{-1}$ EP and $2.0 \times 10^{-3} \mathrm{~mol} \mathrm{~L}^{-1}$ AA (2) in PBS (pH 4.0) by CV. As shown in (2), the oxidation peaks of EP and AA can be separated on the GME. This means that GME can be used for the
Table 2 Determination of EP by proposed method $(n=6)$

\begin{tabular}{ccccr}
\hline Sample & $\begin{array}{c}\text { EP sample/ } \\
\times 10^{-5} \mathrm{~mol} \mathrm{~L}^{-1}\end{array}$ & $\begin{array}{c}\text { EP standard/ } \\
\times 10^{-5} \mathrm{~mol} \mathrm{~L}^{-1}\end{array}$ & $\begin{array}{c}\text { Total EP/ } \\
\times 10^{-5} \mathrm{~mol} \mathrm{~L}^{-1}\end{array}$ & $\begin{array}{c}\text { Recovery, } \\
\%\end{array}$ \\
\hline 1 & 3.08 & 3.00 & 5.98 & 96.7 \\
2 & 2.98 & 3.00 & 5.95 & 99.0 \\
3 & 3.02 & 3.00 & 6.05 & 101.0 \\
\hline
\end{tabular}

discrimination of EP in the presence of AA.

The effects of the other substances that often accompany EP in various pharmaceutical preparations were studied by analyzing a standard solution of EP $\left(5.0 \times 10^{-5} \mathrm{~mol} \mathrm{~L}^{-1}\right)$. If a foreign species caused a relative error of less than $\pm 5 \%$ during the determination of $5.0 \times 10^{-5} \mathrm{~mol} \mathrm{~L}^{-1} \mathrm{EP}$, it was considered to be no interference. No interference has been found when including up to $1000 \mu \mathrm{mol} \mathrm{L}-1$ of $\mathrm{K}^{+}, \mathrm{Na}^{+}, \mathrm{Ca}^{2+}, \mathrm{NH}_{4}^{+}, \mathrm{Mg}^{2+}$, $\mathrm{Cl}^{-}, \beta$-alanine, $100 \mu \mathrm{mol} \mathrm{L}{ }^{-1}$ of glucose and tartaric acid.

\section{Applications}

The present method was used for the determination of EP in three kinds of EP samples. Pharmaceutical injections were diluted in $50 \mathrm{~mL}$ brown volumetric flasks separately. An aliquot of diluted EP was mixed with a certain amount of AA $\left(C_{\mathrm{AA}} / C_{\mathrm{EP}}=1000\right)$, and further diluted with PBS ( $\left.\mathrm{pH} 4.0\right)$ in another $50 \mathrm{~mL}$ brown volumetric flask. EP in these preparations was determined by $\mathrm{CV}$ using the GME, respectively. The recoveries were calculated according to the oxidation peak currents. These results (Table 2) show that the novel GME is a potential tool for the selective determination of EP in the presence of AA.

\section{Conclusions}

A novel and simple strategy for the selective detection of EP using GME is presented in this paper. The GME showed efficient electro-catalytic activity through cyclic voltammetry. Complete peak separation between EP and AA, obtained from $\mathrm{CV}$ curves, and demonstrated that graphene influenced the electron transfer of EP and AA. Based on this finding, graphene 
can be used as an advanced carbon-based electrode material for the selective determination of EP.

\section{Acknowledgements}

This work was financially supported from the Shandong City High School Science and Technology Fund Planning Project of J10LB64.

\section{References}

1. P. Hernandez, O. Sanchez, F. Paton, and L. Hernandez, Talanta, 1998, 46, 985.

2. T. N. Deftereos, A. C. Calokerinos, and C. E. Efstathiou, Analyst, 1993, 118, 627.

3. M. A. Dayton, J. C. Brown, K. J. Stutts, and R. M. Wightman, Anal. Chem., 1980, 52, 946.

4. K. Pihel, T. J. Schroeder, and R. M. Wightman, Anal. Chem., 1994, 66, 4532.

5. H. S. Wang, D. Q. Huang, and R. M. Liu, J. Electroanal. Chem., 2004, 570, 83.

6. S. F. Wang, D. Du, and Q. C. Zou, Talanta, 2002, 57, 687.

7. G. Erdogdu, J. Anal. Chem., 2002, 57, 741.

8. A. Salimi, C. E. Banks, and R. G. Compton, Analyst, 2004, $129,225$.

9. A. K. Geim and K. S. Novoselov, Nat. Mater., 2007, 6, 183.
10. K. S. Novoselov, A. K. Geim, S. V. Morozov, D. Jiang, Y. Zhang, S. V. Dubonos, I. V. Grigorieva, and A. A. Firsov, Science, 2004, 306, 666.

11. L. A. Ponomarenko, F. Schedin, M. I. Katsnelson, R. Yang, E. W. Hill, K. S. Novoselov, and A. K. Geim, Science, 2008, 320, 356.

12. K. S. Novoselov, Z. Jiang, Y. Zhang, S. V. Morozov, H. L. Stormer, U. Zeitler, J. C. Maan, G. S. Boebinger, P. Kim, and A. K. Geim, Science, 2007, 315, 1379.

13. S. Stankovich, D. A. Dikin, G. H. B. Dommmett, K. M. Kohlhaas, E. J. Zimney, E. A. Stach, R. D. Piner, S. T. Nguyen, and R. S. Ruoff, Nature, 2006, 442, 282.

14. S. Watcharotone, D. A. Dikin, S. Stankovich, R. Piner, I. Jung, H. B. Dommett, G. Evmenenko, S. E. Wu, S. F. Chen, C. P. Liu, S. T. Nguyen, and R. S. Ruoff, Nano Lett., 2007, 7, 1888.

15. W. S. Hummers, Jr. and R. E. Offeman, J. Am. Chem. Soc., 1958, 80, 1339.

16. L. Fu, H. B. Liu, and Y. H. Zou, Carbon, 2005, 4, 10.

17. Y. C. Si and E. T. Samulski, Nano Lett., 2008, 8(6), 1679.

18. L. H. Tang, Y. Wang, Y. M. Li, H. B. Feng, J. Lu, and J. H. Li, Adv. Funct. Mater., 2009, 19, 2782.

19. X. L. Wen, Y. H. Jia, and Z. L. Liu, Talanta, 1999, 50, 1027.

20. J. Wang and A. Walcarius, J. Electroanal. Chem., 1996, 407, 183.

21. S. M. Chen and K. T. Peng, J. Electroanal. Chem., 2003, $547,179$. 